\title{
Assessment of Nurses' Knowledge and Practice for Patients Undergoing Radical Cystectomy Surgeries
}

\author{
Shaimaa Abd El-Hameid Hussein ${ }^{1}$, Ahmed Awad Sayed ${ }^{2}$, Hala Mohammed Ghanem ${ }^{3}$ \& Hanan Abd El - \\ Razik Abd El- all ${ }^{4}$. \\ 1. Master Degree Nursing. Supervisor nurse at South Egypt Cancer Institute, Assiut University, Egypt. \\ 2. Professor of Surgical Oncology, South Egypt Cancer Institute, Assiut University, Egypt. \\ 3. Assistant Professor of Medical- Surgical Nursing, Faculty of Nursing, Assiut University, Egypt. \\ 4. Lecturer of Medical- Surgical Nursing Faculty of Nursing, Assiut University, Egypt.
}

\begin{abstract}
Background: The patient who undergoing radical cystectomy has needs many nursing care because of alterations in the functional health patterns of elimination, health, management, cognitive, self-perception and role relationships. Aim of the study: This study aimed to assess nurse's knowledge and practice regarding patients undergoing Radical cystectomy surgeries. Research design: Descriptive research design was utilized in this study. Setting: The study was conducted at the Surgical Oncology Department at South Egypt Cancer Institute. Sample: A convenience sample including (60) nurses working at surgical oncology department who are willing to participate in the study. Tools: Structured interview questionnaire sheet, and observation checklist sheet. Results: the majority of nurses had unsatisfactory knowledge as regarding radical cystectomy surgeries. The score knowledge about specific care after procedure was higher $(\mathrm{Mean} \pm \mathrm{SD}=2.42 \pm 3.2)$ in compared to other items including; Radical cystectomy surgeries, nursing care before cystectomy, and general care after cystectomy. The majority of nurses were inadequate of their practice regarding postoperative instruction before discharge with (mean $\mathrm{SD}=33.78 \pm 3.77$ ). Conclusion: a significant statistical difference between nurses knowledge in relation to total mean knowledge score, a significance statistical difference between nurses practice in relation to total mean practice score. Recommendations: nurses need for in- service training programs and refreshing courses to improve knowledge which will reflect into their knowledge and practice while work with patients.
\end{abstract}

\section{Keywords: Radical Cystectomy \& Surgeries.}

\section{Introduction}

Bladder cancer (BC) is the most common malignancy of the urinary tract, the 7 th most common cancer in men and the 17th in women (Brausi, 2011). In the United States, BC is the fourth most common cancer and the eight leading cause of cancer-related death in humans (Fry \& Vahabi, 2016).

Cystectomy is the surgical removal of all or part of the bladder. It is used to treat bladder cancer that has spread into the bladder wall (Berglund \& Herr, 2012). Radical cystectomy is the recommended treatment for bladder cancer that has invaded the muscle of the bladder (Boron, et al., 2016).

A radical cystectomy is most commonly performed for cancer that has invaded into the muscle of the bladder. In a radical cystectomy the bladder is removed along with surrounding lymph nodes (lymph node dissection) and other organs that contain cancer. In men, this could include the prostate and seminal vesicles. In women, this could include a portion of the vagina, uterus, fallopian tubes, and ovaries (Welty, et al., 2017).

Worldwide, BC accounts approximately estimated in the United States at the years of (2018) about
$(81,190)$ new cases of bladder cancer about $(62,380)$ in men and $(18,810)$ in women and about $(17,240)$ deaths about $(12,520)$ in men and 4,720 in women (American Cancer Society, 2018).

In developed areas of the world, such as North America and Western Europe, these BC are predominantly urothelial (transitional cells). Nonurothelial tumors comprise a larger fraction of disease in other areas, particularly where schistosomiasis is prevalent (Fiorina, et al., 2018).

In Egypt at the years of $2017 \mathrm{BC}$ represent $(1,775$ males and 411 females; 784 SCC and 1,402 UC) in both sexes (Fiorina, et al., 2018). During the period from 2017 to 2018 was approximately 1120 cases in both sexes admitted to surgery department at South Egypt Cancer Institute (South Egypt Cancer Institute Records, 2018).

National Comprehensive Cancer Network (NCCN) guidelines recommend radical cystectomy as the primary treatment for patients with muscle-invasive bladder cancer, whereas alternative treatments are reserved for patients with extensive comorbid conditions or poor performance status (Montie, et al., 2010). 
Radical cystectomy involves removal of the urinary bladder and associated organs; the prostate in men, and the uterus, ovaries, and part of the vagina in women. Urinary diversion procedures are performed to divert urine to a new exit site, usually through a surgically created opening (stoma) in the skin. These procedures are primarily performed when a bladder tumor necessitates removal of the entire bladder (Schoenberg \& Gonzalgo, 2016).

The patient who undergoes radical cystectomy surgeries has many nursing care needs because of alterations in the functional health patterns of elimination, health perception-health management, cognitive perceptual, self perception, role relationships and quality of life. The nurse will be responsible for monitoring the patient's vital signs, fluid status (stoma/catheter output, drains, intravenous fluids, nasogastric tube) need for analgesia and the administration of prescribed medication (Oshea, 2011).

The nurse should also monitor the stoma to ensure it remains pink and healthy in appearance. The patient will also require wound care and help with activities of daily living in the immediate postoperative

period. Specialist input from other healthcare professionals such as stoma care nurses, physiotherapists and dieticians may also help (Gerharz, et al., 2015).

Furthermore, this research could provide health professionals with an in depth understanding related to such patients which could be reflected positively on the quality of patient's life and improve the postoperative patient's health outcomes. It is hoped also that this effort could support the role of the nurse in the patient's care through assessing and providing the required care and teaching about adapting and living with stoma reaching their maximum functional capacity.

\section{Significance of the study}

Careful monitoring of the viability of the stoma and recognition of stoma ischemia as a particular nursing responsibility could have a great impact upon the success of the urostomy. Provided that, stoma clinic is newly introduced into South' Egypt Cancer Institute and the nurses working in this clinic did not received any special preparation to help them deal safely with such conditions as expressed by them. So this research could be an attempt to equip this group of nurses with needed knowledge and practices that could contribute to stoma care.

\section{Aim of the Study}

The aim of the present study was to assess nurses' knowledge and practice regarding patients undergoing Radical cystectomy surgeries.

\section{Patients \& Methods}

\section{Research design}

Descriptive research design was utilized in this study.

I-Technical design

Setting of the study

The study was conducted at the surgical oncology department and outpatient stoma clinic in South Egypt Cancer Institute.

\section{Study sample}

A sample of convenience including all available nurses working at surgical oncology department and outpatient stoma clinic (60) nurses who are willing to participate in the study.

\section{Study tools}

Data pertinent to the study were collected and utilized the following three tools that developed by researcher based on recent relevant review to achieve the purpose of the current study.

Tool I- Structured interview questionnaire sheet This tool was developed and modified by the researcher after reviewing and utilizing the most recent relevant national \& international literature, review to assess nurses' knowledge about radical cystectomy surgeries. It was constructed based on the following two parts:

Tools (I) it consists of two parts

Part (1): Demographic data of nurses; to assess the personal data for the study sample which including (6) items as, sex, age, martial status, qualification, duration of experience, and training courses about radical cystectomy.

Part (2): Nurses' knowledge about radical cystectomy surgeries; (Vancouver General Hospital, 2016). To assess their knowledge about care of patient undergoing radical cystectomy surgeries which include 3 main parts as, a nurses knowledge about definition of bladder cancer, causes of bladder cancer, signs \& symptoms of bladder cancer, types of bladder cancer, contraindications for radical cystectomy surgeries and complications after radical cystectomy surgeries. It included 18 items and consists of 3 main parts:

1. Nurse's knowledge about radical cystectomy surgeries, which includes3 questions.

2. Nurses' knowledge about nursing care before radical cystectomy surgeries to assess the general and specific nursing care, which includes 2questions.

3. Nurses knowledge about nursing care after radical cystectomy surgeries to assess routine nursing care, care of pain, care of stoma, instruction for patient before discharge which includes 13 questions.

The questionnaire sheet was administered by the 
researcher to the nurses for answering all its components then collected. The total number was (18) questions.

\section{Scoring system}

Each right answer was given one score and zero for false answer. The total scores were 24. Those who obtained less than $(60 \%)$ were considered having unsatisfactory level of knowledge. From (60\%) and above were considered having satisfactory level.

Tool II- An observation checklist sheet of nurses: (Vancouver General Hospital, 2016).

This tool was constructed after reviewing related literature review and accordingly a modification was done. It was used to assess nurses practice of radical cystectomy surgeries nursing activities during providing care for those patients. It was designed to include 3 steps checklist.

That are most commonly used, nursing activities as follows: general preoperative care, immediate postoperative nursing care and preventive measure for postoperative discomfort for radical cystectomy patients.

Observed of activities or skill done takes 1 and not done takes zero.

\section{Scoring system}

For the nurses practice was degree, the essential items take a higher degree below $60 \%$ was regarded in adequate and $60 \%$ and above was regarded as adequate.

\section{II-Operational Design}

\section{Administrative design}

An official letter was issued from the dean of the faculty of nursing to the head of the surgical oncology department as well as the head of nursing service administration soliciting the necessary approval to conduct the present research. Meetings with nursing supervisors and physicians of the surgical oncology department to explain the objectives and the methods of the study.

Technique for data collection: This study was carried out in two phases

Phase (1): Preparatory phase: in which the researcher was designed after extensive literature review (nursing text books, journals, internet resources, etc.) about cystectomy surgeries and assessment of nurse's knowledge and practice in this regard will be checked by panel of 5 experts to list content validity, this phase ended by a pilot study.

Content validity; it was established by panel of 5 experts who reviewed the instruments for clarity, relevance, comprehensive understanding, applicability and easiness for administrative minor modifications were required.

Pilot study; A pilot study was carried out in 2017to test the feasibility and predictability of the study tools applied on $10 \%$ (6 nurses) of the sample size nurses. It had also provided an estimate of the time needed to fill out the tools, no change was done in the assessment sheet, so the nurses selected for the pilot study were included in the main study. The purpose of the pilot study was to ascertain the relevance of tool, to detect any problem peculiar to the statements clarity that might interfere with the process of data collection.to estimate the time needed to complete the interviews schedule total before pilot and after (60) nurse .

Phase (2): Implementation phase: once permission was granted to proceed with the proposed study, the researcher initiated data collection. thehead nurse of the surgical oncology department and the hospital nursing director who helped the researcher to accomplish this work.

Data were collected at surgical oncology department during the period from (March, 2017 to February, 2018). The tools were filled through interviewing. The purpose of the study was explained to the nurse prior to answering the questions. An observational checklist was carried out what the nurses were on duty during morning and afternoon shifts (20 sheets every month).

Each nurse was observed by the researcher two times at different duties: once in the morning shift \& once in the afternoon, while they were performing nursing activities for their patients by using the direct observation technique.

\section{Statistical design}

Descriptive \& inferential statistics was utilized Data were collected and analyzed by computer program SPSS-12 statistical soft were package and excel for figures. Data expressed as mean, standard deviation, number and percentage. T-test is used to determine significant for numeric variable. Chi-square test is used to determine significant for non-parametric variable.

\section{Ethical and legal consideration}

1) Research proposal was approved from Ethical committee in the faculty of nursing.

2) There is no risk for study subject during application of the research.

3) The study was followed common ethical principles in clinical research.

4) Written consent was obtained from patients or guidance who are willing to participate in the study, after explaining the nature and purpose of the study.

5) Confidentiality and anonymity was assured.

6) Study subject have the right to refuse to participate and or withdraw from the study without any rational any time.

7) Study subject privacy was considered during collection of data. 


\section{Results}

Table (1): Frequency distribution of studied nurses as regarding their demographic characteristics $(n=60)$.

\begin{tabular}{|c|c|c|}
\hline Characteristics & Frequency & \\
\hline Gender: & No & $\%$ \\
\hline - Male & 7 & 11.7 \\
\hline - $\quad$ Female & 53 & 88.3 \\
\hline \multicolumn{3}{|l|}{ Age: } \\
\hline$-\quad<20$ years & 4 & 6.7 \\
\hline - $\quad$ from $20>30$ years & 32 & 53.3 \\
\hline - $\quad$ from 30 to 40 years & 24 & 40.0 \\
\hline Mean \pm SD & \multicolumn{2}{|c|}{$26.85 \pm 4.92$} \\
\hline \multicolumn{3}{|l|}{ Marital status: } \\
\hline - Single & 11 & 18.3 \\
\hline - $\quad$ Married & 49 & 81.7 \\
\hline \multicolumn{3}{|l|}{ Level of education: } \\
\hline - $\quad$ Diploma in Nursing & 45 & 75.0 \\
\hline - $\quad$ Instituted of Nursing & 5 & 7.0 \\
\hline - $\quad$ Bachelor of Nursing & 10 & 18.0 \\
\hline \multicolumn{3}{|l|}{ Year of experience: } \\
\hline$-\quad<1$ years & 3 & 5.0 \\
\hline$-\quad$ From $1-<5$ years & 18 & 30.0 \\
\hline - $\quad$ From $5-10$ years & 15 & 25.0 \\
\hline - $\quad$ More than 10 years & 24 & 40.0 \\
\hline Mean \pm SD & \multicolumn{2}{|c|}{$7.74 \pm 4.98$} \\
\hline Training courses for cystectomy surgeries: & & \\
\hline$-\quad$ Yes & 4 & 6.7 \\
\hline$-\quad$ No & 56 & 93.3 \\
\hline
\end{tabular}

Table (2): Frequency distribution of the mean of nurse's knowledge scores obtained by nurses as regard radical cystectomy surgeries $(n=60)$.

\begin{tabular}{|l|c|c|c|}
\hline \multicolumn{1}{|c|}{ Knowledge items } & maximum scores & Mean \pm SD & T-test \\
\hline -Radical cystectomy surgeries & 6 & $1.67 \pm 1.71$ & $\mathbf{- 1 6 . 4 9 9}$ \\
\hline -Nursing care before cystectomy & 2 & $0.18 \pm 0.39$ & $\mathbf{- 1 3 . 2 6 0}$ \\
\hline -General care after cystectomy & 2 & $0.82 \pm 0.47$ & $\mathbf{- 1 5 . 0 3 3}$ \\
\hline -Specific care after procedure & 11 & $2.42 \pm 3.2$ & $\mathbf{- 1 6 . 9 0 9}$ \\
\hline - Total Knowledge score & 21 & $5.08 \pm 4.94$ & $\mathbf{- 1 9 . 3 2 1}$ \\
\hline
\end{tabular}

Independent T-test ${ }^{* *}$ Significant difference at p. value $<0.01$

Table (3): Frequency distribution for the mean total knowledge scores obtained by nurses as regarding radical cystectomy surgeries $(n=60)$.

\begin{tabular}{|l|c|c|c|}
\hline \multirow{2}{*}{\multicolumn{1}{|c|}{ Nurses knowledge }} & \multicolumn{2}{c|}{ (n=60) } & \multirow{2}{*}{ P. value } \\
\cline { 2 - 3 } & No. & \% & \multirow{2}{*}{$<0.001 * *$} \\
\hline Satisfactory & 7 & 11.7 & \\
\hline Un satisfactory & 53 & 88.3 & \\
\hline Mean \pm SD & \multicolumn{2}{|c|}{$5.08 \pm 4.94$} & \\
\hline
\end{tabular}


Table (4): the mean total practice scores obtained by nurses about radical cystectomy surgeries $(n=60)$.

\begin{tabular}{|l|c|c|c|}
\hline \multicolumn{1}{|c|}{ Practice items } & Maximum scores & Mean \pm SD & T-test \\
\hline -General pre-operative nursing care & 14 & $9.63 \pm 1.39$ & -24.340 \\
\hline -Specific pre-operative nursing care & 34 & $13.43 \pm 3.68$ & -43.121 \\
\hline -Immediate post-operative nursing care & 42 & $19.57 \pm 6.07$ & -28.354 \\
\hline -Preventive measures for post-operative discomfort & 40 & $22.72 \pm 5.45$ & -24.505 \\
\hline -Post-operative instruction before discharge & 80 & $33.78 \pm 3.77$ & -94.492 \\
\hline -Total practice scores & 210 & $99.13 \pm 15.36$ & -55.721 \\
\hline
\end{tabular}

Independent T-test $* *$ Significant difference at p. value $<0.01$

Table (5): Correlation between nurses knowledge and practice scores obtained by nurses $(\mathbf{n}=60)$.

\begin{tabular}{|c|c|c|c|c|c|}
\hline \multirow{3}{*}{ knowledge score } & \multicolumn{4}{|c|}{ practice score } & \multirow{3}{*}{ P. value } \\
\hline & \multicolumn{2}{|c|}{ Inadequate $(60)$} & \multicolumn{2}{|c|}{ Adequate(60) } & \\
\hline & No. & $\%$ & No & $\%$ & \\
\hline - Un satisfactory & 53 & 88.3 & 1 & 1.7 & \multirow{2}{*}{$<0.001 * *$} \\
\hline - $\quad$ Satisfactory & 7 & 11.7 & 60 & 98.3 & \\
\hline
\end{tabular}

**Statistically Significant Correlation at p. value $<0.01$

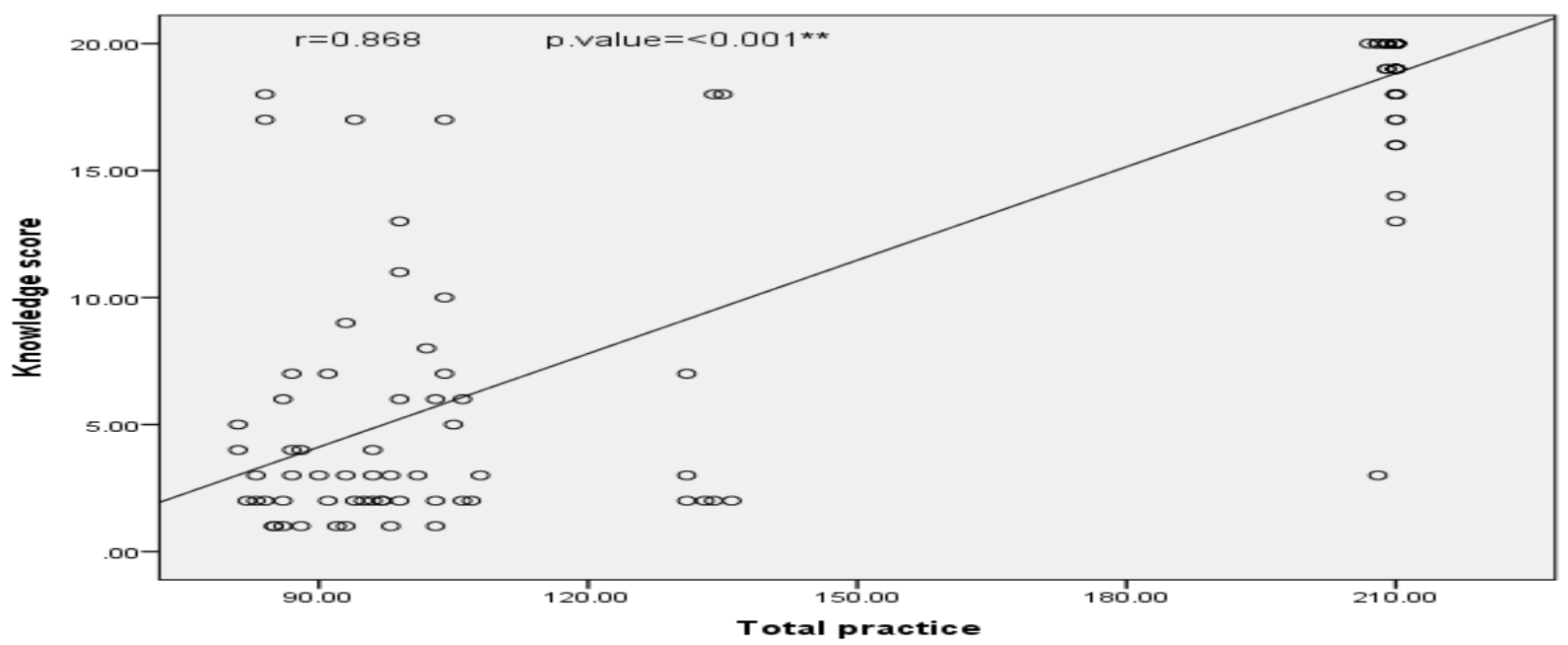

Fig (1): Correlation between nurse's knowledge and practice scores.

Table (1): Showed that; The majority of the nurses $(88.3 \%)$ were female. More than half of nurses $(53.3 \%)$ their age ranged from $20>30$ years with Mean of the age group was $(26.85 \pm 4.92)$ and had diploma of nursing $(75.0 \%)$, the majority of nurses were married $(81.7 \%)$ and the majority of the nurses no had attended training programs $(93.3 \%)$. Less than half of the nurses $(40.0 \%)$ their years of experience more than 10years with Mean of years was $(7.74 \pm 4.98)$.

Table (2): Demonstrated that; The nurses had unsatisfactory level of knowledge as regarding nursing care for patient undergoing radical cystectomy surgeries with mean 5.08 \pm 4.94 .

Table (3): Shows that; The majority of nurses (88.3) had unsatisfactory level of knowledge as regard nursing care for patient undergoing radical cystectomy surgeries mean $(5.08 \pm 4.94)$ and highly significant statistical difference between nurses knowledge in relation to total score with p.value $<0.001^{* *}$ as regarding radical cystectomy surgeries.

Table (4): Illustrated that; A Significant statistical difference was found between nurses practice in relation to total mean practice scores in all practice items.

Table (5) \& Fig (1): Illustrates that; A significant statistically correlation between knowledge score and practice score with $\mathrm{p}$. value $<0.001$.

\section{Discussion}

Patient education about bladder management after radical cystectomy begins before surgery and is 
restarted as soon as possible after surgery. While education focuses on the nurses, patient, family members and other care providers. Any educational intervention can change patients' outcomes including knowledge, skills, attitudes, behaviors, condition or status, resulting from their involvement in a program or service.

Nursing teaching is an important and potentially powerful tool that can have beneficial effects that include improvement in nurses' knowledge, self-care, quality of care, cost reduction, transparency of treatment, and staff satisfaction with benefits of training and education (Carroll \& Susan, 2015).

The results of the present study showed that the highest percentages of nurses are female. More than half of nurses their age ranged from $20>30$ years and had diploma of nursing. The majority of nurses are married and the highest percentage of nurses not attended training programs. Less than half of nurses, their years of experience more than 10 years.

This finding in the line with study by Abd Al-Magid (2011) reported the majority of nurses aged from 2040 years, female, have diploma in nursing and their experience more than 3 years. Also the result supported by Ahmed (2011), Marquis\& Huston, (2009); stated that education and training are two components of staff development that occur after radical cystectomy (which refers to planned, guided adjustment of employee to the organization and work environment). Knowledge level and capabilities are a major factor in determining the number of staff required to carry out unit goals.

This result may be attributed to insufficient courses related to cystectomy included in their undergraduate curriculum of nursing education. Most nurses stated that their knowledge gained while working with patients. Also there is no Arabic source for updating and continuing their education. So BSN nurses have important aid to education of other nurses to improve their knowledge.

This result contradicted with Xyrichis, (2007) who stated that multi professional education within tissue viability is vital if patients are to receive optimum care and this education should commence at undergraduate level. However, after qualifying, time pressures within healthcare areas can prove to be a barrier for staff wishing to access courses. Staff often rely on advice from peers who may themselves not have accessed the most up-to-date information which can prevent development of evidence based interventions.

In the present study, the majority of nurses had unsatisfactory level of knowledge regarding contraindications to conduct the cystectomy operation, routine nursing cares given to patients after cystectomy, precautions must be met to avoid infection of wound and measuring vital signs immediately after operation.

This result disagree with Cooks, (2011) stated that the nurse is responsible and accountable for the quality of nursing care given to patients. The single most important protective strategy for the nurse is to be a knowledgeable and safe practitioner of nursing and to meet the standards of care with all patients. Nurses are empowered by the SOC and the trust of the physician and the patient to ensure quality care.

In the present study, most of nurses in the present study show unsatisfactory level of knowledge about primary nursing care given to patients before cystectomy, information about nursing care of pain and use of the abdominal belt, instruction that must be given to patients before discharge and the position for patients immediately after operation.

In this regards Lemone \& Burke (2009), stressed on providing standard nursing care for patients who had radical cystectomy surgeries is grounded on a solid foundation of knowledge.

Most nurses their knowledge gained while working with patients. Books that were given to them during their secondary learning years were taken from them at the end of years and there is no arabic source for updating and continuing their education. Also this may be attributed to lack of continuous education and absence of in-service training program.

Dell Anna \& Anaclerio, (2015), reported that to accomplish quality care and best possible outcome; nurses should be knowledgeable about the type of surgery planned, its course and possible complications. Kristen, (2012), stated that medical surgical nurses must recognize post operative complications that may arise. These results are in agreement with those of Meyer \& Elliott (2009), who noted that nurses` knowledge scores were higher among younger and newly graduated, nurses who attending training program.

The current study showed inadequate level of total practice scores in all items regarding pre and postoperative care for patients who had radical cystectomy surgeries. All nurses didn't perform adequate care and didn't do adequate assessment for general pre-operative nursing care, specific preoperative nursing care, immediate post operative nursing care and preventive measures for postoperative discomfort. This may be due to all nurses didn't have enough information about absence of nursing care related to postoperative patients care who radical cystectomy surgeries.

This result were in the same line with Marquis \& Huston, (2009), who reported that each organization and profession must set standards and objectives to 
guide individuals and practitioners in performing safe and effective care. Leader and managers also must see that subordinates know and understand the standards and employee must be aware that their performance will be measured in terms of their ability to meet the established outcomes.

Regarding patients` instructions before discharge, the present results showed that nurses give inadequate instructions to patients who had radical cystectomy surgeries before discharge. In this regards Kumrow, (2012), stated that discharge teaching for postoperative patient should include information regarding the signs and symptoms of potential complications, when and how contact to the physician, written and verbal information regarding medication, wound care and follow up visits with the physician.

The nurse must be aware that the patient demonstrates an understanding of all aspects of home care and emphasized on the family and significant others who are included in discharge teaching.

So, it can be concluded that results from this study and other studies strongly suggest that teaching should be approached in an organized manner, under pinned by sound principles of teaching and learning using teaching plans where appropriate to ensure that no vital aspects are omitted. Also, patient who undergoing radical cystectomy surgeries resulting in an abdominal stoma need extensive teaching and counseling to fully recover.

Finally, it can be concluded that, the teaching for nurses working with patients undergoing radical cystectomy surgeries had achieved its objectives by improving nurses' knowledge and practice about postoperative monitoring of cystectomy surgeries.

\section{Conclusion \& Recommendations Conclusions}

Based on the results of the present study, it can be concluded that,

- Patient with radical cystectomy surgeries were at high risk for postoperative complications which in turn increase the development of complications of stoma. These complications include acidosis, leaking urine or stool, bowel obstruction, kidney infection, obstruction of the ureters or intestines, renal failure, problems with opening (stoma) and scar tissue that forms inside the intestines as previously mentioned in the literature and need effective measures to prevent| reduce this considerable profound physical problem.

- Nurse's knowledge and practice regarding radical cystectomy surgeries in surgical oncology department at South Egypt Cancer Institute are inadequate.

- Application of nursing teaching about care of patients undergoing radical cystectomy surgeries shows a significance improvement in nurses' knowledge and practice. Improving nurses' knowledge and practice can favorable affect the incidence and outcome of radical systectomy surgeries.

\section{Recommendations}

Based on the results of the present study, it can be recommended that

- Continued nursing education and in service training programs in surgical oncology department should be well organized within south Egypt Cancer Institute and equipped with the necessary educational facilities and materials necessary to upgrade the knowledge and skills of nurses, which will be reflected on better outcome and service for patients.

- Nurses should add to their routine obligations the regular reading of update references (periodicals, textbooks, etc.). They should always be encouraged to attend scientific meetings and conferences to keep pace with the rapidly growing wealth of knowledge and practice necessary for proper nursing service.

- Periodic monitoring of nurses knowledge and practice.

- Replication of the study on a large probability sample acquired from different geographical areas in Egypt to figure out the main aspects of this problems.

\section{References}

1. Abd-Alla, M., (2012): Assuring quality care through a managerial inservice training program for head nurses working in Assiut University Hospital, DNS thesis of nursing service administration, Assiut University, review of literature, pp.20-25.

2. Abd Al- Mageed, A., (2011): Nursing care standards for cancer patients undergoing chemotherapy, submitted for partial fulfillment of the requirements of Doctorate Degree in Adult Nursing, Faculty of Nursing, Assiut University, discussion part, PP.112-115.

3. Abdel-Hady E., (2016): Life Satisfaction and General Well- Being among Bladder Cancer Patients Undergoing Radical Cystectomy with Illeal Conduit Diversion. OSR Journal of Nursing and Health Science. Vol. (5), No. (2), pp. 68-74.

4. Ahmed, R., (2011): Developing postoperative 
care standards for patients who had drainage of chronic subdural hematoma, thesis submitted for partial fulfillment of the requirements of master degree in Adult Nursing, Faculty of Nursing, Assiut University, discussion part, PP.102.

5. American Cancer Society. Cancer facts \& figures, (2018): Available at: https://www.cancer.org/content/dam/cancerorg/research/cancerfacts-and-statistics/annualcancer-facts-and-figures/2018/cancer-facts-andfigures; Vol. (501 c), No. (3), pp. (8).

6. Berglund R., Herr H., (2012): Surgery of bladder cancer. Campbell-Walsh Urology, Philadelphia: Saunders Vol. (2), Issue. (10), Chp. (40), pp. 2375-2385.

7. Boron, Walter F., Boulpaep, Emile L., (2016): Medical Physiology From molecules to systems E- Book. Vol. (1), No. (3), pp. 738.

8. Carroll, V., \& Susan, (2015): Role of the environment of the operating suite in surgical wound infection, Lippincott Williams and Wilkins, Inc., Vol.(74), Issue.(6), pp. 784-795.

9. Cooks D., (2010): DSHS Nursing Standards of care and Nursing Standards of performance p.1.

10. Dell Anna, G., Anaclerio, G., (2015): Nursing management in surgery, European institute of oncology, Italy; Vol.(3), No.(8), pp.675-756.

11. Fiorina Kyritsi, Christopher A., Loffredo, Yun-Ling Zheng, George Philips, SaniaAmr, (2018): https://doi.org, Vol. (2018), No. (10), pp.16-23.

12. Fry, C., Vahabi, B., (2016): "The Role of the Mucosa in Normal and Abnormal Bladder Function". Basic \& clinical pharmacology \& toxicology. Vol. (119), Issue. (S3), pp.17-20.

13. Gerharz E., Weingärtner K., Dopatka T., Köhl U., Basler H., Riedmiller H., (2015): Quality of life after cystectomy and urinary diversion: results of a retrospective interdisciplinary study; Vol. (174), No. (5), pp.1729-1736.

14. Jack W., McAninch, Tom F., Lue, Smith \& Tanagho's, (2008): Urinary Diversion \& Bladder Substitutions; No. (18), Chp. (25), pp. 1120-1121.

15. Janice L., Kerry H., Brenda G., Suzzane C., Connell S., (2010): Brunner \& Suddarth's Textbook of Medical-Surgical Nursing. Management of Patients with Urinary Disorders; Vol. (1), Issue. (12 th) ed, pp. 13471348.

16. Kristen, D., (2012): The bladder, physiology and pathology, neonatal network; Vol. (19), No. (8), pp.11:40.
17. Lemon, P., Burke, K., (2009): MedicalSurgical Nursing critical thinking in client, Published on the internet http://www.findarticles.com; Vol. (4th Edit), No. (9), pp. (879).

18. LeMone P., Dwyer T., (2009): Nursing care of people with urinary tract disorder. MedicalSurgical Nursing; Vol. (2009), No. (5), pp. 869.

19. Marquis, L., \& Huston, J., (2009): Leader ship roles and management functions in nursing, Lippincott, Hong Kong; Vol. (32), No. (6th) ed, pp.371.

20. Meyer, R., \& Elliott, R., (2009): Pathway excellence, A peer based program in continuing education, J Cont Educ Nurs; Vol. (27), No. (3), pp. 104.

21. Montie J., Clark P., Eisenberger M., (2010): Bladder cancer; J Natl Compr Canc Netw; Vol. (7), No. (1), pp. 8-39.

22. Oshea, H., (2011): Teaching the adult ostomy patient. Journal of wound ostomy continence Nursing, Vol. (28), No. (1), PP. 47-54.

23. Salem H., (2012): Changing patterns (age, incidence, and pathologic types) of schistosomaassociated bladder cancer in Egypt in the past decade Urology; Vol. (79), No. (2), pp. 379383.

24. Schoenberg M., Gonzalgo M., (2016): Management of invasive and metastatic bladder cancer. Campbell-Walsh Urology. Philadelphia, PA: Saunders; Issue. (9th)ed, pp. 2468-2478.

25. South Egypt Cancer Institute Record, (2018).

26. Vancouver General Hospital, (2016): part of the Vancouver Coastal Health Authority. Enhanced Recovery after Surgery (ERAS) for radical cystectomy; 2016. Available at: http://enhancedrecoverybc.ca/wpcontent/uploads/2015/02/ERAS-RadicalCystectomy-pathway-2016_VG.

27. Welty. C., Sanford, J., Wright, (2017): “The Cancer of the Bladder Risk Assessment (COBRA) score: estimating mortality after radical cystectomy," Cancer;Vol. (123), No. (23), pp. 4574-4582.

28. World Health Organization , (2017): Available at: http://www.afro.who.int/healthtopics/schistosomiasis-bilharzia.

Xyrichis A., Lowton K., (2007): What fosters or prevents inter professional team working in primary \& community care? A literature review. 